\title{
Advancing islet transplantation: from engraftment to the immune response
}

\author{
R. F. Gibly • J. G. Graham • X. Luo • W. L. Lowe Jr • \\ B. J. Hering $\cdot$ L. D. Shea
}

Received: 18 April 2011 / Accepted: 21 June 2011 /Published online: 10 August 2011

(C) Springer-Verlag 2011

\begin{abstract}
The promise and progress of islet transplantation for treating type 1 diabetes has been challenged by obstacles to patient accessibility and long-term graft function that may be overcome by integrating emerging technologies in biomaterials, drug delivery and immunomodulation. The hepatic microenvironment and traditional systemic immunosuppression stress the vulnerable islets and contribute to the limited success of transplantation. Locally delivering extracellular matrix proteins and trophic factors can enhance transplantation at extrahepatic sites by promoting islet engraftment, revascularisation and longterm function while avoiding unintended systemic effects. Cell- and cytokine-based therapies for immune cell recruitment and reprogramming can inhibit local and systemic immune system activation that normally attacks transplanted islets. Combined with antigen-specific immunotherapies, states of operational tolerance may be achievable, reducing or eliminating the long-term pharmaceutical burden. Integration of these technologies to enhance engraftment and combat rejection may help to
\end{abstract}

R. F. Gibly · J. G. Graham • L. D. Shea

Institute of Bionanotechnology in Medicine (IBNAM),

Northwestern University,

Chicago, IL, USA

R. F. Gibly • J. G. Graham

Integrated Graduate Program, Northwestern University,

Chicago, IL, USA

X. Luo $\cdot$ W. L. Lowe Jr

Department of Medicine, Northwestern University,

Chicago, IL, USA

B. J. Hering

Department of Surgery, University of Minnesota,

Minneapolis, MN, USA advance the therapeutic efficacy and availability of islet transplantation.

Keywords Biomaterial · Biotechnology · Diabetes . Extrahepatic - Immunomodulation - Islet transplantation . Review. Scaffold $\cdot$ Tissue engineering $\cdot$ Tolerance

$\begin{array}{ll}\text { Abbreviations } \\ \text { APC } & \text { Antigen-presenting cell } \\ \text { BAX } & \text { BCL2-associated X protein } \\ \text { DC } & \text { Dendritic cell } \\ \text { ECDI } & \text { Ethylcarbodiimide } \\ \text { ECM } & \text { Extracellular matrix } \\ \text { IBMIR } & \text { Instant blood-mediated inflammatory reaction } \\ \text { iTreg } & \text { Induced Treg } \\ \text { MSC } & \text { Mesenchymal stem cell } \\ \text { nTreg } & \text { Natural Treg } \\ \text { PLG } & \text { Copolymer of lactide and glycolide } \\ \text { Treg } & \text { Regulatory T cell } \\ \text { VEGF } & \text { Vascular endothelial growth factor }\end{array}$

B. J. Hering

Schulze Diabetes Institute, University of Minnesota, Minneapolis, MN, USA

L. D. Shea $(\square)$

Department of Chemical and Biological Engineering,

Northwestern University,

2145 Sheridan Rd/E136,

Evanston, IL 60208, USA

e-mail: 1-shea@northwestern.edu

L. D. Shea

Chemistry of Life Processes Institute, Northwestern University,

Evanston, IL, USA

L. D. Shea

Robert H. Lurie Comprehensive Cancer Center,

Northwestern University,

Chicago, IL, USA 


\section{Introduction}

Human islet transplantation might become an effective cure for the significant subgroup of type 1 diabetic patients in whom the improvements in diabetes care are inadequate to prevent frequent acute and/or debilitating chronic complications [13]. Iatrogenic hypoglycaemia is the most limiting factor in the glycaemic management of type 1 diabetes and, despite advances in glucose-monitoring technology, serious hypoglycaemic events (leading to physical and psychological morbidity, including coma, seizures and death) have not abated since being highlighted by the DCCT in 1993 [1]. Chronic micro- and macrovascular complications have also remained a major source of morbidity and mortality in diabetic patients, with data suggesting that major declines in total mortality and renal failure rates reflect better management and that complications are delayed rather than prevented [2]. Despite advances in monitoring and therapeutics, morbidity and mortality remain increased in type 1 diabetic patients compared with non-diabetic populations [4]. After more than three decades of investigation, human islet transplantation as a beta cell replacement strategy reached a major milestone in 2000 when investigators in Edmonton achieved diabetes reversal in seven out of seven recipients by using islets from more than one donor pancreas and corticosteroid-free immunosuppression [3]. Since then, remarkable advances have demonstrated insulin independence with islets from a single donor and allograft survival sustained with calcineurin inhibitor-free protocols $[5,6]$. Preliminary data even suggest that long-term insulin independence ( $>5$ years) can be achieved in $45-50 \%$ of recipients given $\mathrm{T}$ cell-depleting induction immunotherapy, matching insulin independence rates of solitary pancreas transplantation [7]. Encouragingly, reports have confirmed that even partial graft function after transplantation is remarkably effective in protecting against severe hypoglycaemic events, while a prospective clinical trial demonstrated a reduced progression of diabetic nephropathy and retinopathy after islet transplantation compared with the progression with intensive medical therapy [8]. These data highlight the immense potential of cell-based diabetes therapy.

A decade of research working to improve intrahepatic islet delivery has identified multiple mechanisms that limit islet engraftment and function long-term. Intrahepatic transplantation is a minimally invasive portal infusion that results in islet entrapment within hepatic sinusoids. This vascular space provides nutritional and physical support for islets; an essential role given that isolation strips the islets of their dense vasculature and specialised extracellular matrix (ECM) [9]. However, the hepatic portal vasculature can be considered as a hostile environment that limits islet engraftment and function [10]. Vascular delivery results in an instant blood-mediated inflammatory reaction (IBMIR) - an activation of the complement and coagulation cascades and infiltration of leucocytes that can lead to the loss of up to twothirds of the islets within the first few days post transplant [10, 11]. Surviving islets within the hepatic portal environment experience low oxygen tension, high glucose levels, and first-pass exposure to metabolites and pharmaceuticals. Immunosuppressive drugs that concentrate in the liver can be toxic to the islets, yet must be taken for the lifetime of the graft $[12,13]$. Intrahepatic islets are poorly revascularised compared with native islets in the pancreas or islets transplanted at other sites [14]. Intrahepatically transplanted islets may also be lost as a result of localised, insulin-induced hepatic steatosis, lipotoxicity and inflammation [15]. These influences can damage the islets, and long-term studies have identified the non-immune-mediated loss of function from intrahepatically transplanted islets [16]. Research continues to increase the success rate of portal delivery; however, the local milieu of intrahepatically delivered islets cannot be readily manipulated and provides a significant challenge to substantive improvements.

A transformative approach to islet transplantation may be achieved through the adaptation of technologies (see text box: Biotechnologies for advanced approaches to extrahepatic islet transplantation) for locally controlling the transplant microenvironment to promote engraftment and long-term function while minimising or eliminating systemic non-specific immunosuppression with local immunomodulation or operational tolerance induction. An extravascular, extrahepatic approach eliminates the IBMIR, while a biomaterial platform can locally provide biomolecular signals such as ECM proteins or trophic factors that may promote engraftment, function and beta cell turnover, which may be an important part of long-term function [9, 17-19]. In addition, the transplant microenvironment can be designed to modulate inflammation, immune cell infiltration and activation associated with the auto- and allo-immune responses, which may synergise with systemic tolerance-inducing therapies [20]. Reducing or eliminating the systemic immunosuppressive load will lower the islet toxicity associated with immunosuppression. It will also reduce the burden on patients and may significantly enhance the maintenance of insulin independence. This local control of the transplant microenvironment can enable enhancement of islet engraftment, survival and function in ways not possible with intrahepatic delivery. These technologies may reduce the islet mass needed, thereby increasing availability and patient access, yet will also contribute to cell therapies involving alternative beta cell sources, such as xenogeneic islets or engineered insulin-producing cells (reviewed elsewhere [21]). This review describes technologies with local and systemic effects that can be used in a combinatorial approach, enabling extrahepatic transplantation to surpass the effectiveness of intraportal delivery and transforming islet transplantation into a more widespread and effective therapy for type 1 diabetes. 


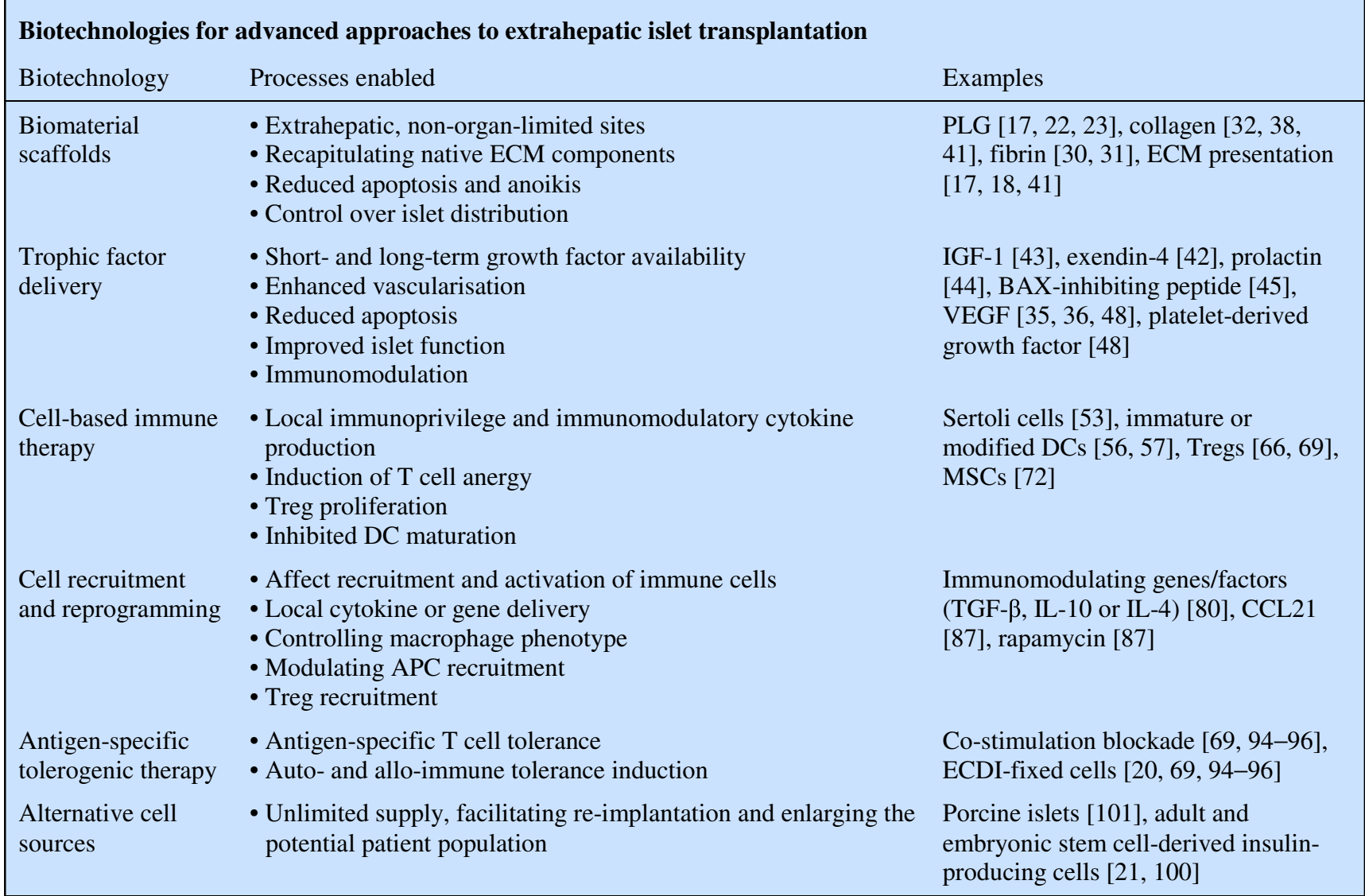

\section{Engraftment}

Immediately following transplantation, islets are avascular, significantly stressed and susceptible to apoptosis and necrosis induced by multiple processes. The challenges associated with islet survival, integration with the host and long-term function are illustrated in Fig. 1. The sections below discuss these challenges and identify opportunities to improve transplant outcomes using technologies for controlling the local islet environment. Biomaterials, ECM proteins, trophic factors and cell co-transplantation can be employed to promote engraftment, thereby reducing the number of islets needed for transplantation and supporting long-term function.

Biomaterial scaffolds Natural or synthetic biomaterials can be employed to engineer an extrahepatic space to localise islets and control the microenvironment after transplantation [17, 22, 23]. Biomaterial-based approaches have traditionally involved encapsulation and isolation; however, some scaffolds have been developed that encourage host integration [17, 22, 23]. A biomaterial scaffold can provide a support that enables transplantation at extrahepatic and extravascular sites, which will avoid the negative influences of the liver environment and the IBMIR [24, 25].
Importantly, biomaterial scaffolds implanted extrahepatically may be retrievable, which could facilitate the adoption of insulin-producing cells derived from stem cells. Several alternative sites such as organ capsules, bowel loops and submucosal areas have been studied [24]. Sites such as the central nervous system or testes can offer a degree of immune protection [26, 27], whereas the omental fat or gastric and intestinal submucosa can recapitulate the islets' native portal venous drainage; facilitating physiological insulin and glucose responsiveness [23, 28]. The anterior chamber of the eye has recently been demonstrated to be an accessible islet transplant site in a pre-clinical baboon model of diabetes [29]. This site offers convenient posttransplant monitoring and potential immune privilege, and appears to have minimal impact on the physiology and function of the eye. Important challenges for many of these alternative implantation sites are the volume of cells being delivered and the inability to control the transplant microenvironment beyond the endogenous physiology. As an example, the kidney capsule is a gold-standard site in murine research, yet clinical translation has been prevented because of the required islet mass [24].

An emerging vehicle for islet transplantation has been porous scaffolds. Islets can readily be seeded into the pores, while the porosity supports rapid cell infiltration for 


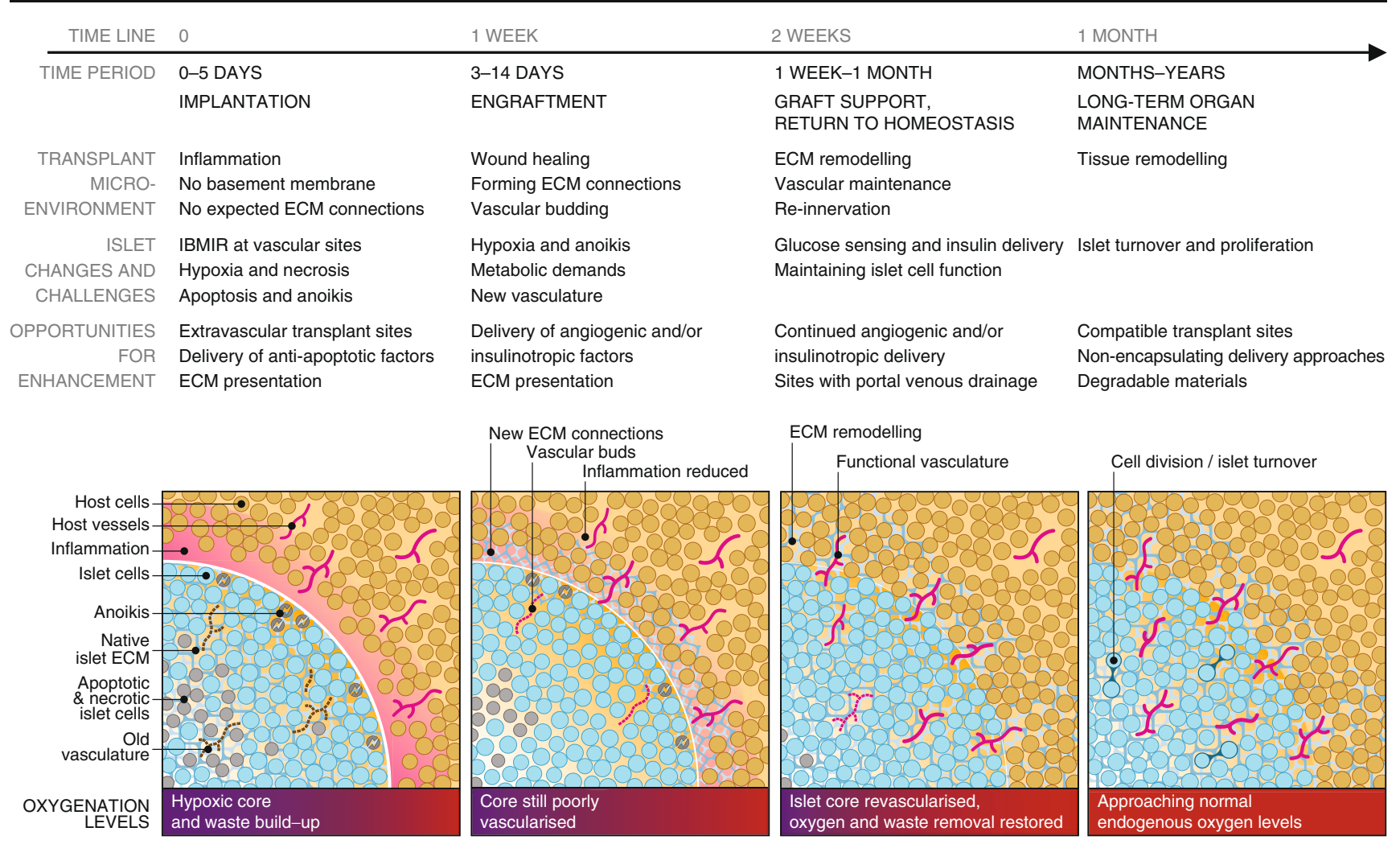

Fig. 1 Timeline of transplanted islet engraftment. Islets require a period of weeks to become engrafted within host tissue. Immediately following implantation, islets are avascular and isolated from host tissue in an inflammatory environment. Islet cells are stressed at this early phase and may undergo anoikis, apoptosis and necrosis as a result of the foreign ECM and inadequate oxygenation and nutrient/ waste exchange. ECM remodelling and angiogenesis in the transplant microenvironment and islet tissue are key parts of the islet engraftment process. The figure illustrates and describes the timeline of islet engraftment in host tissue from implantation to long-term maintenance, detailing the changes occurring in the transplant microenvironment and within islets, and challenges to function and survival. The understanding of this process enables the identification of opportunities for enhancing islet engraftment, survival and function throughout the process. These opportunities for enhancement and ways to achieve them are discussed in detail in the article text integration with the host tissue. Microporous scaffolds composed of the biocompatible, biodegradable copolymer of lactide and glycolide (PLG), approved by the US Food and Drug Administration, create and maintain a space for transplanted islets while enabling control of their distribution and density $[17,20,22]$. The high porosity enables nutrient diffusion, rapid host tissue infiltration and islet revascularisation. Degradable hydrogels such as collagen, fibrin and clotted plasma can similarly support rapid ingrowth and revascularisation [30-32]. As with the porous PLG scaffolds, they are completely degraded, enabling uninterrupted reintegration with the host [17, 22]. Adoption of PLG scaffolds for extrahepatic islet transplantation has additionally been demonstrated to enhance systemic tolerance induction relative to traditional hepatic infusion [20]. The alternative approach to engraftment is isolation, typically attempted with non-degradable natural or synthetic hydrogels such as alginate and polyethylene glycol [33, 34]. These hydrogels may prevent cellular attack by the immune system but also prevent cell ingrowth, vascularisa- tion and re-innnervation, which could potentially affect glucose sensing, insulin secretion and long-term beta cell turnover [19].

A critical consideration for transplantation is the reestablishment of a functional vasculature to support efficient glucose sensing and the large metabolic demand of transplanted islets. Encapsulation strategies may result in vascular growth around the materials, yet these vessels cannot directly connect with the islets. Non-encapsulating strategies aimed at host islet integration allow the surrounding vasculature to sprout and reconnect with the islets. Technologies have been employed for transplant site prevascularisation, localised expression or delivery of angiogenic growth factors, or cell co-transplantation to improve post-transplant vascularisation and subsequent islet function and engraftment [35-39].

Biomaterial-based strategies can also present ECM proteins in an organised fashion to transplanted islets. The islet-ECM interaction provides critically important islet survival signals, and the enzymatic and mechanical isola- 
tion process disrupts the specialised islet basement membrane of ECM proteins $[9,40]$. Using biomaterial technology to provide ECM proteins to islets can significantly enhance engraftment and function as they provide a structural support while binding cell-surface integrins that mediate adhesion and activate intracellular signalling pathways $[17,41]$. Islet death in the early post-transplantation period may be related to a loss of integrin signalling that results in apoptosis - a process known as anoikis [18, 40]. In vitro and in vivo, ECM components reduce apoptosis and improve islet function and viability [17, 18]. Biomaterial surfaces or hydrogels can be formed or modified with ECM molecules, adhesive peptides or other biochemical signals to enhance engraftment and transplantation [17].

Trophic factors Trophic factor delivery may stimulate specific cellular processes associated with islet survival and engraftment to maximise transplant success. Insulinotropic factors such as IGF-1, exendin-4 and prolactin, or anti-apoptotic factors like BCL2-associated X protein (BAX)-inhibiting peptide have enhanced transplanted islet survival and function [42-45]. IGF-1 has been linked to regulation of beta cell mass, proliferation and regeneration [43]. Exendin-4 is a long-acting glucagon-like peptide-1 agonist that stimulates beta cell proliferation, protects against apoptosis and improves outcomes in islet transplantation [42]. Prolactin signalling during pregnancy is responsible for beta cell proliferation, and prolactin pre-incubation and injection have been shown to improve transplanted islet engraftment and revascularisation [44]. Pre-treatment with or induced production of BAX-inhibiting peptide in islet transplants can enhance engraftment by minimising apoptosis [45], which is a major contributor to islet loss in the early post-transplant period, triggered by cues such as loss of ECM contacts, DNA damage, hypoxia and nutrient starvation [10]. Finally, delivery of angiogenic factors such as vascular endothelial growth factor (VEGF) can enhance islet engraftment and glucose sensing by improving revascularisation [35]. Maximising islet engraftment efficiency may not be achieved with a single 'silver bullet' and may require a tailored combination of factors.

The systemic delivery of trophic factors is complicated by the required doses, short half-lives, and side effects on non-target tissues. For example, the half-life of glucagonlike peptide-1 makes it ineffective for systemic therapy, and its long-acting agonist, exendin-4 (exenatide) is frequently discontinued by patients owing to side effects [42, 46]. Systemic delivery of factors such as prolactin is not possible because of hormonal effects on other tissues, while angiogenic and anti-apoptotic factors face significant hurdles because of the potential for pathological vascularisation or tumour growth. Short-term local delivery can be achieved with relatively simple approaches, such as injection or pre- treatment in culture. Conversely, sustained-release technologies could ensure the availability of these factors during the critical days to weeks following transplantation while avoiding off-target effects. Biodegradable polymers have been used extensively to deliver everything from small molecule drugs to large bioactive proteins and the genes encoding these proteins [47-49]. Multiple factors can be delivered simultaneously, and delivery can be tailored to persist for days to weeks [48]. PLG microspheres are an established platform for localised factor delivery to a target site. Alternatively, factors may be delivered directly from the scaffold used for transplantation, with the scaffold functioning as a support for growth and a vehicle for sustained release [48, 49]. For example, localised production or pre-treatment with angiogenic factors such as VEGF and platelet-derived growth factor have been employed to improve vascularisation and subsequent islet function and engraftment $[35,36]$. Alternatively, angiogenic factors have been delivered to pre-vascularise a site prior to transplantation [37, 38].

Taken together, the findings to date indicate that the current portal infusion model provides limited opportunities for modulating the islet environment to promote engraftment. Alternative sites and biomaterial scaffolds can serve as a platform for presenting multiple biochemical signals, with the ability to create a structured extrahepatic microenvironment containing native ECM proteins and delivering trophic factors. These technologies could revolutionise the post-transplantation environment of islets, providing a foundation for long-term function.

\section{Immunity in islet transplantation}

Immunosuppressive agents are typically delivered systemically to address the underlying autoimmunity as well as the allo-immune responses to transplanted islets. These immunosuppressants are permanently needed following transplantation and have multiple unavoidable side effects, such as an increased vulnerability to infection for the patient and cytotoxicity to the transplanted islets (many are diabetogenic) [13]. Although immunosuppressive therapy has improved over time, with the identification of new drugs and combinations, targeted modulation of the innate and adaptive immune response to transplanted islets may provide a pathway to reduce or eliminate systemic immunosuppression (Fig. 2).

Immuno-engineering microenvironments to prevent rejection of the transplanted islets is a concept inspired by immunoprivileged sites such as the testes [27], anterior chamber of the eye [29], the brain [26] and, more recently, by studies of cancer [50]. At these sites, specialised cells produce immunomodulatory molecules and physical barriers 


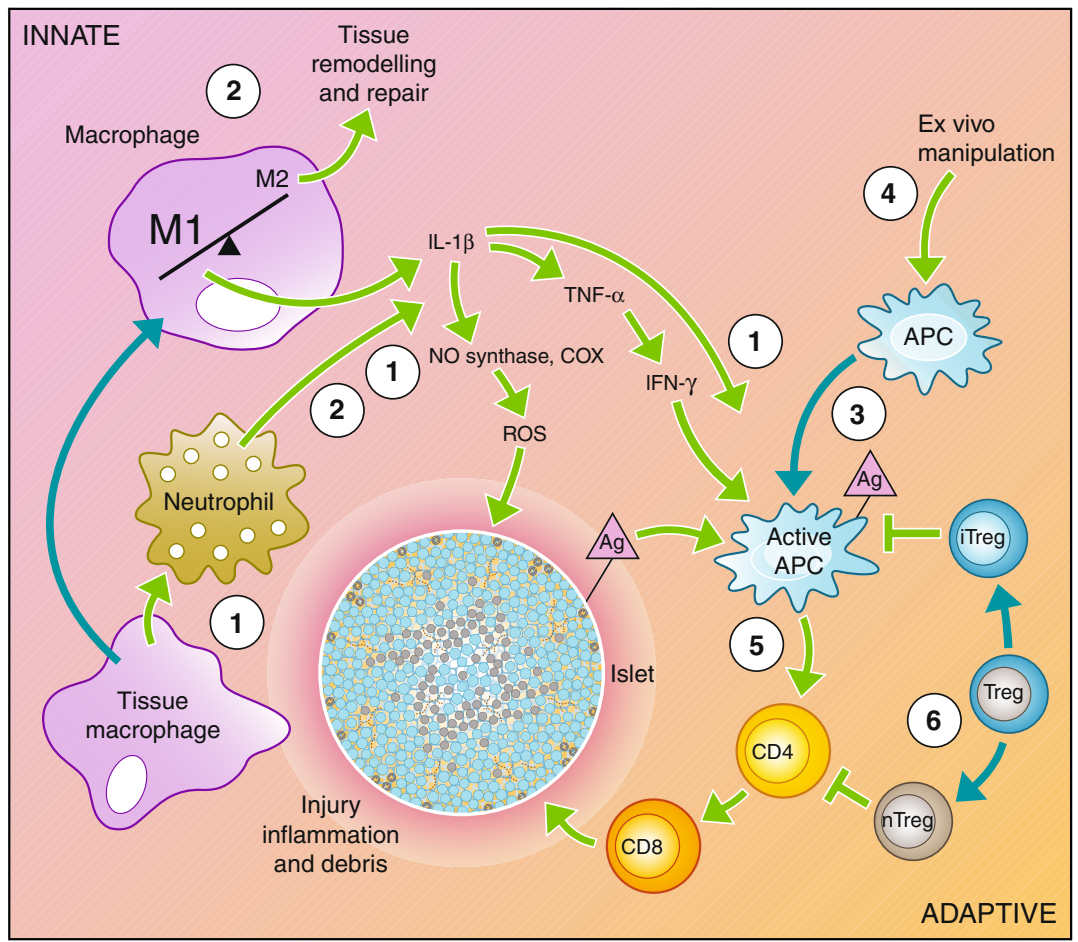

\section{INTERVENTIONS}

(1) Anti-inflammatory agents

(2) Immunomodulatory cytokines

(3) APC activation/phenotype

(4) Primed DCs

(5) Co-stimulatory molecule block

(6) Treg expansion

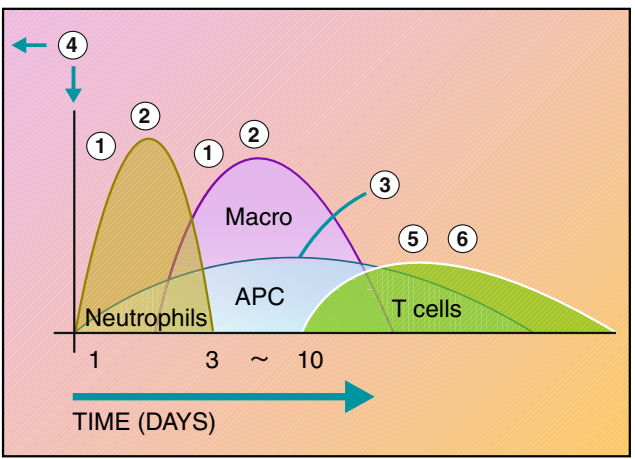

Fig. 2 Recipient immune response to transplanted islets. The recipient immune system is activated through the initial surgical trauma and introduction of foreign material. In addition, damage to the islets causes the release of antigen $(\mathrm{Ag})$ into the environment. The innate immune system responds through macrophage and neutrophil activation, causing inflammation in the microenvironment and infiltration of additional immune cells into the graft. Macrophages and neutrophils initiate a cascade through the release inflammatory cytokines and reactive oxygen species that activate the antigenpresenting cells (APCs) and damage the islet. Active APCs activate

against immune cell infiltration. While these sites may not accommodate the volume of islets needed for transplantation, they have inspired attempts to recreate those physical and biochemical microenvironments. These strategies do not typically remove auto- or alloreactivity; rather, they strive for operational tolerance, defined as a sustained antigenspecific unresponsiveness in the absence of chronic immunosuppression [51]. This operational tolerance represents a balance between immunity and rejection that can enable stable graft function for extended times, yet can be broken under certain circumstances [52]. The process of immune recognition and immune destruction of transplanted cells has been described following multiple steps: (1) inflammation; (2) maturation of dendritic cells (DCs) and migration to draining lymph nodes; (3) T cell activation by DCs, resulting in expansion of anti-donor T cells; and (4) migration of T cells to the graft where they mediate cytotoxicity [50]. The following paragraphs describe emerging technologies targeting one or more steps in immune recognition and immune destruction, either locally at the site of transplant or systemically in the draining lymph node and spleen, that could enhance engraftment and reduce or alter the non-specific immunosuppression. helper T cells (CD4) that continue to activate cytotoxic T cells (CD8), which destroy the islet. Regulatory T cells maintain APCs and helper $\mathrm{T}$ cells in inactive states, preventing the adaptive immune response from destroying the islet. The diagram to the right depicts the timeline and types of infiltrating cells in the graft site following transplantation. A number of interventions aimed at interrupting the immune cascade are listed to the right, and their point of action is indicated by the corresponding numbers on the diagram. These interventions are detailed in the article text

Cell-based immune therapy Biomaterial scaffolds allow islets to be co-localised with other transplanted cell types to create an immunoprivileged environment that induces operational tolerance. Hepatic infusions of multiple cell populations may not result in consistent co-localisation of each cell population, which is readily achievable using a scaffold. Some immunomodulatory cell types (e.g. regulatory $\mathrm{T}$ cells) can be delivered intravenously and would be expected to home to the graft site. A complication of this approach is the large number of cells that may be required for efficacy, which can potentially be reduced by co-localising the islets with these cells. The potential for co-localisation of cells has been illustrated with Sertoli cells from the testes, which normally provide a physical barrier to immune system infiltration and produce immunomodulatory molecules such as TGF- $\beta$, IL-10 and Fas ligand. Co-transplantation of islets with Sertoli cells in the kidney capsule has extended allogeneic graft survival, demonstrating that an immunoprivileged zone can be created by an immunomodulatory cell type that enables long-term graft survival [53]. 
DCs have been targeted by therapies to limit their activation, which would normally prohibit the development of operational tolerance [54]. Ordinarily, host antigenpresenting cells (APCs), such as DCs, encounter foreign antigens and become activated, displaying the antigen to the immune system, resulting in an inflammatory cascade and destructive environment. Maintaining APCs in an immature state influences their migration dynamics to draining lymph nodes, and prevents them from upregulating the co-stimulatory molecules that activate other immune cells [55]. Immature donor DCs lacking the co-stimulatory molecules for immune system activation can promote tolerance and allograft survival by inducing allo-antigenspecific T cell anergy when infused prior to transplantation [56]. Alternatively, donor DCs manipulated to present antigens under a plasmacytoid phenotype can promote host regulatory $\mathrm{T}$ cell (Treg) differentiation [57]. APCs can be manipulated to present antigens under a plasmacytoid phenotype in the absence of co-stimulatory molecules [58], potentially tolerising the host immune system through anergy of allo-antigen specific effector $\mathrm{T}$ cells. Recipient DCs loaded with allopeptides and reintroduced intravenously can inhibit $\mathrm{T}$ cell activation in the periphery and thymus [59]. Also, recipient DCs treated with IL-10 and TGF- $\beta$ in vitro induced Treg proliferation, T cell anergy, and prevented graft vs host disease in allotransplantation $[60,61]$. Both donor and recipient DCs can thus be manipulated to make the host immune system more tolerant of transplantation.

The transplantation of Tregs has been employed to harness the intrinsic mechanisms of immunomodulation. Tregs can suppress immune activation in models of autoimmune disease and allotransplant rejection. Two types of $\mathrm{CD} 4^{+} \mathrm{CD} 25^{+} \mathrm{Foxp}^{+}$Tregs exist in the periphery and have this suppressive capability: natural Tregs (nTregs) are thymic-derived, whereas induced Tregs (iTregs) differentiate from $\mathrm{CD} 4^{+} \mathrm{CD} 25^{-} \mathrm{Foxp}^{-} \mathrm{T}$ cells in the periphery. The nTregs maintain immunological homeostasis and selftolerance in the periphery by suppressing self-reactive $\mathrm{T}$ cell function with the help of peripheral APCs [62]. The iTregs secrete IL-10 and TGF- $\beta$ to control the maturation and activation of DCs and $\mathrm{CD}^{+} \mathrm{T}$ cells (key cellular immune initiators and modulators), preventing their subsequent migration to draining lymph nodes [63-65]. Antigenspecific Tregs have been generated ex vivo, and following intravenous delivery they home to transplantation sites and the draining lymph nodes, suppressing the allo-immune response [66, 67]. Direct co-transplantation of Tregs with islets localises them directly to the graft site rather than relying on homing, which may reduce the number required [66, 68, 69].

Mesenchymal stem cells (MSCs) have demonstrated significant potential for a range of transplantation applica- tions, with modulation of the immune response a key target for enhancing graft function. In a transplantation setting, MSC suppression of the adaptive immune response has been reported to occur via modulation of $\mathrm{DC}$ and $\mathrm{T}$ cell activity. One mechanism of action is the pushing of DCs toward a tolerogenic phenotype by inhibiting their maturation through downregulation of co-stimulatory molecules and other maturation markers [70]. In addition, MSCs decrease DC secretion of TNF- $\alpha$ and increase plasmacytoid DC production of IL-10. By inhibiting DC maturation, MSCs inhibit T cell activation and the release of additional inflammatory cytokines. MSCs similarly affect the generation of Tregs, which regulate the maturation of DCs and T cells [70] and inhibit T cell division through the secretion of TGF- $\beta 1$ [71]. Beyond immunomodulation, MSCs have been demonstrated to enhance wound healing, with implications for islet engraftment. MSCs infused with islets have improved diabetes reversal, prolonged graft survival and enhanced islet function in non-human primate allogeneic islet transplantation. Additional infusions of MSCs during rejection episodes further prolonged graft survival [72]. Taken as a whole, MSCs have positive effects on wound healing and immunoprotection and have the potential to enhance islet transplantation when cotransplanted with islets.

Cell recruitment and reprogramming The surgical intervention and introduction of foreign cells recruits neutrophils and macrophages, which respond by releasing proinflammatory cytokines and lipid mediators that recruit more inflammatory cells and influence engraftment [73]. For intrahepatic transplantation, resident macrophages (Kupffer cells) secrete cytokines, nitric oxide, and free radicals, which are directly toxic to the islets [10]. During the early inflammatory response, macrophages and neutrophils contribute to the secretion of IL- $1 \beta$ [56] and TNF- $\alpha$ [57], which result in the release of toxic species and induce islet dysfunction [74]. IL-1 $\beta$ also upregulates the expression of the genes for, and enzymatic activity of, inducible nitric oxide synthase and cyclooxygenase-2, which leads to further dysfunction and apoptosis. Thus, activated macrophages and neutrophils may be key contributors to the significant loss of islets in the days following transplantation. In addition to direct effects on transplanted islets, secreted cytokines perpetuate the inflammatory process and enhance the invasion and differentiation of additional inflammatory cells such as T cells [75]. IL-1 $\beta$ (and TNF- $\alpha$ or IFN- $\gamma$ by induced IL- $\beta$ secretion) directly activates multiple inflammatory cell types, such as DCs, which continue to stimulate a cascade of immune cells including $\mathrm{CD}^{+}$helper and $\mathrm{CD}^{+}$killer $\mathrm{T}$ cells [76]. Despite this inflammatory response, the long-term survival and function of some transplanted islets suggests that this response may 
specifically influence initial engraftment, increasing the number of islets required for transplant success [10].

Strategies for controlling innate immunity (e.g. macrophage activation) are a crucial first step in operational tolerance. Activated protein $\mathrm{C}$, which limits procoagulant and proinflammatory responses, has been used to limit IBMIR and thereby enhance islet survival [77-79]. Localised delivery of cytokines and other factors can similarly modulate the innate immune response and thus subvert the inflammatory cascade, potentially enhancing islet survival and limiting activation of the adaptive immune response. Macrophages have phenotypes described as a continuum ranging from M1 (inflammatory) to M2 (anti-inflammatory or regenerative), with M2 promoting processes such as angiogenesis that enhance engraftment. Factors such as TGF- $\beta$, IL-10 and IL-4 have the potential to upregulate the expression of genes associated with M2 while decreasing gene expression associated with M1 [80]. These same factors inhibit neutrophil recruitment and the release of proinflammatory cytokines and chemokines [81, 82]. As described above, these factors could be delivered as proteins for weeks to months, or alternatively, as gene therapy vectors to obtain prolonged expression of these factors [83]. Providing a few factors locally may turn macrophages or DCs into assets for islet engraftment by interrupting inflammation at an early stage and thereby limiting DC activation and migration.

Studies of cancer have indicated the potential to create local immunoprivilege despite systemic immunity. The release or expression of specific factors may be employed to recruit specific cell populations, reprogramming cell function to induce operational tolerance. Localised delivery has been able to modulate the type of APCs entering an implant [84], providing the opportunity to reprogramme APCs and influence their function should they migrate to the draining lymph node or spleen [85]. Treg migration into the graft site and the draining lymph node can facilitate tolerance induction to self- and allogeneic antigens, and factors such as CCL21 may function to recruit Tregs to such sites [86]. Similarly, rapamycin, a classic immunosuppressant, has been reported to expand Treg populations in vivo and possibly induce tolerance [87]. Alternatively, localised delivery of the factors produced by Tregs could be used to control other immune cell responses. T cellmediated cytotoxicity at the implant site may be limited through delivery of CTLA-4-Ig, a genetically engineered fusion protein of human cytotoxic T lymphocyte antigen 4 (CTLA-4) and the IgG $1 \mathrm{Fc}$ region that can prevent $\mathrm{T}$ cell activation by binding to human B7, which co-stimulates T cells through CD28. Cells producing CTLA-4-Ig had a prolonged allograft survival, even in the absence of detectable levels of CTLA-4-Ig in the serum [88]. Alternatively, stromal cell derived factor- 1 may act as a $\mathrm{T}$ cell chemo-repellent, as localised production increases survival of the allograft and significantly reduces $\mathrm{T}$ cell infiltration [89]. The evidence to date indicates that localised delivery or expression of these and other factors [50] may affect the recruitment and activation of immune cells, which can facilitate the induction of operational tolerance.

Lymph node and splenic targeting In addition to locally modulating the immune response around transplanted islets, technologies that target immune responses within the draining lymph node or spleen may be necessary to establish operational tolerance. A site with exclusive lymphatic drainage may require modulation of only the transplant and the corresponding draining lymphatic tissue. Recent work has demonstrated the potential of developing nanoparticles that accumulate in lymph nodes and if delivered from the transplant site would likely target the draining lymph nodes [90]. These nanoparticles have been used for vaccines and the potential exists to adapt the technology for the blockade rather than induction of $\mathrm{T}$ cell activation.

Despite the advances in pan-immunosuppression via antibody therapies, an antigen-specific approach is desirable to avoid the numerous side effects inherent to this type of immunosuppression. Several powerful systemic allogeneic tolerance therapies have been studied, including donorspecific transfusion with co-stimulation blockade (antiCD40 ligand), anti-CD3 or anti-CD4 therapies [91-93]. Monoclonal antibodies targeting autoreactive $\mathrm{T}$ cells have ameliorated disease in autoimmune models [94]. A recent example of targeted tolerance induction in allogeneic islet transplantation uses a pre- and post-transplant infusion of donor cells chemically fixed with ethylcarbodiimide (ECDI) to direct the host immune response. This powerful and safe method to induce antigen-specific $\mathrm{T}$ cell tolerance has been demonstrated in several in vivo autoimmune models, including thyroiditis, uveitis, experimental autoimmune encephalomyelitis and, most recently, to prevent allogeneic islet transplant rejection [20, 95-97]. In nonobese diabetic mouse models, this approach has enabled prevention of autoimmune diabetes onset as well as reversal of early stage diabetes [68]. However, the specific mechanisms by which ECDI-treated cells induce antigen-specific tolerance are not yet completely understood (reviewed in [98]). In allogeneic islet transplantation, tolerance is accomplished at least partially by deleting antigen-specific effector $\mathrm{T}$ cells, effectively resetting the host immune system to accept donor-specific allo-antigens and by upregulating the number and function of Tregs. Maintenance of long-term tolerance requires an interaction between effector T cells, Tregs, APCs and the graft in the local microenvironment [68]. This tolerance induction has recently been demonstrated to work more effectively for 
islets transplanted on biomaterials at an extrahepatic site as compared with intra-portal infusion [20]. Thus, technologies such as the ECDI-based treatment combined with local immunomodulation can enable effective long-term tolerance to islet allografts [20].

\section{A multi-pronged approach for long-term success}

As described above, an extrahepatic strategy that has an emphasis on localised control to encourage islet engraftment, survival and function and is capable of delivering trophic factors and incorporating advanced immunomodulation or tolerance-inducing strategies could provide a foundation for transformative advances in islet transplantation. Given the complexity of transplantation and the underlying disease, prioritising the development of platform technologies may be required to address the multitude of barriers to effective engraftment and long-term function. Biomaterial scaffolds can define an extrahepatic site and present matrix proteins to the transplanted cells, while providing a vehicle for either drug delivery to provide trophic factors or immunomodulators, or cell cotransplantation to target a range of local cellular processes. The trafficking of immune cells through the transplant site provides an opportunity to modulate them, which will influence the responses in the lymph node and spleen, determining the extent of the immune response and affecting tolerogenic strategies. A multi-pronged approach such as this could reduce the islet requirement and immunosuppressive burden associated with the current portal infusion model and produce greater long-term success.

A significant decrease in the immunosuppressive burden and islet requirement per patient would dramatically increase the availability of islet transplantation as a patient therapy. Reduction of the immunosuppressive burden with locally induced immunoprivilege, the use of immunoprivileged sites such as the anterior chamber of the eye, or tolerance induction would eliminate a major hurdle to applicability, especially in young patients. Donor organ availability for islet transplantation is arguably the largest hurdle to widespread applicability. This limited availability is complicated the fact that less than half of islet isolations meet transplant criteria and are large enough for transplantation [99]. Increasing post-transplant islet survival will greatly enlarge the effective islet supply while simultaneously increasing the number of isolations considered large enough for transplantation.

Furthermore, the described strategies for promoting engraftment and modulating the immune response will also facilitate the development of alternative cell sources, which will significantly expand the patient availability of islet transplantation. Alternative sources provide the possibility of a virtually limitless supply of insulin-producing cells (reviewed in $[21,100]$ ). Specially maintained pathogen-free or humanised porcine islets may be the simplest to develop and have proven biological function, but require specific, advanced immunosuppressive or tolerance strategies to prevent xenorejection [101]. Other insulin-producing cells have been successfully derived from a number of sources, including adult and embryonic stem cell sources. Controlling the microenvironment through the use of biomaterials, drug delivery or co-culture could stimulate the biochemical and physical signalling pathways necessary to acquire insulin-producing phenotypes [21, 100]. The localisation of the cells to a scaffold may also be advantageous from a safety perspective, providing the ability to retrieve the implant. Scaffolds can control the localisation of cells, enhancing the development and maintenance of their phenotypes. Thus, biotechnologies to define and modulate a transplant microenvironment have enormous potential to enhance the differentiation, delivery and effectiveness of alternatives to allogeneic islets. In conclusion, the synergy between strategies to promote engraftment and prevent rejection can lead to transformative advances in the effectiveness and availability of islet transplant as a therapy for type 1 diabetes.

Acknowledgements Financial support was provided by grants from NIH \& NIDDK, including: F30 DK846492, R21 EB009502, R01 EB009910, DP2 DK083099 and U01 AI089316.

Contribution statement R.G., J.G.G., X.L., W.L.L. Jr, B.J.H. and L.D.S. were responsible for the conception, writing, revision and development of this manuscript and the figures.

Duality of interest The authors declare that there is no duality of interest associated with this manuscript.

\section{References}

1. Cryer PE (2008) The barrier of hypoglycemia in diabetes. Diabetes 57:3169-3176

2. Pambianco G, Costacou T, Ellis D, Becker DJ, Klein R, Orchard TJ (2006) The 30-year natural history of type 1 diabetes complications: the Pittsburgh Epidemiology of Diabetes Complications Study experience. Diabetes 55:1463-1469

3. Shapiro AM, Lakey JR, Ryan EA et al (2000) Islet transplantation in seven patients with type 1 diabetes mellitus using a glucocorticoid-free immunosuppressive regimen. N Engl J Med 343:230-238

4. Soedamah-Muthu SS, Fuller JH, Mulnier HE, Raleigh VS, Lawrenson RA, Colhoun HM (2006) All-cause mortality rates in patients with type 1 diabetes mellitus compared with a nondiabetic population from the UK general practice research database, 1992-1999. Diabetologia 49:660-666

5. Hering BJ, Kandaswamy R, Ansite JD et al (2005) Single-donor, marginal-dose islet transplantation in patients with type 1 diabetes. JAMA 293:830-835 
6. Posselt AM, Bellin MD, Tavakol M et al (2010) Islet transplantation in type 1 diabetics using an immunosuppressive protocol based on the anti-LFA-1 antibody efalizumab. Am J Transplant 10:1870-1880

7. Hering B, Bellin M, Barton F (2010) Induction immunosuppression with T-cell depleting antibodies facilitates long-term insulin independence after islet allotransplantation in type 1 diabetes. Am J Transplant 10(suppl 4):141-142 (Abstract)

8. Warnock GL, Thompson DM, Meloche RM et al (2008) A multiyear analysis of islet transplantation compared with intensive medical therapy on progression of complications in type 1 diabetes. Transplantation 86:1762-1766

9. Wang RN, Rosenberg L (1999) Maintenance of beta-cell function and survival following islet isolation requires re-establishment of the islet-matrix relationship. J Endocrinol 163:181-190

10. Barshes NR, Wyllie S, Goss JA (2005) Inflammation-mediated dysfunction and apoptosis in pancreatic islet transplantation: implications for intrahepatic grafts. J Leukoc Biol 77:587-597

11. Bennet W, Groth CG, Larsson R, Nilsson B, Korsgren O (2000) Isolated human islets trigger an instant blood mediated inflammatory reaction: implications for intraportal islet transplantation as a treatment for patients with type 1 diabetes. Ups J Med Sci 105:125-133

12. Shapiro AM, Gallant HL, Hao EG et al (2005) The portal immunosuppressive storm: relevance to islet transplantation? Ther Drug Monit 27:35-37

13. Nanji SA, Shapiro AM (2004) Islet transplantation in patients with diabetes mellitus: choice of immunosuppression. BioDrugs $18: 315-328$

14. Lau J, Carlsson PO (2009) Low revascularization of human islets when experimentally transplanted into the liver. Transplantation 87:322-325

15. Lee Y, Ravazzola M, Park BH, Bashmakov YK, Orci L, Unger RH (2007) Metabolic mechanisms of failure of intraportally transplanted pancreatic beta-cells in rats: role of lipotoxicity and prevention by leptin. Diabetes 56:2295-2301

16. Hiller WF, Klempnauer J, Lück R, Steiniger B (1991) Progressive deterioration of endocrine function after intraportal but not kidney subcapsular rat islet transplantation. Diabetes 40:134-140

17. Salvay DM, Rives CB, Zhang X et al (2008) Extracellular matrix protein-coated scaffolds promote the reversal of diabetes after extrahepatic islet transplantation. Transplantation 85:1456-1464

18. Pinkse GG, Bouwman WP, Jiawan-Lalai R, Terpstra OT, Bruijn JA, de Heer E (2006) Integrin signaling via RGD peptides and anti-beta1 antibodies confers resistance to apoptosis in islets of Langerhans. Diabetes 55:312-317

19. Bonner-Weir S, Li WC, Ouziel-Yahalom L, Guo L, Weir GC, Sharma A (2010) Beta-cell growth and regeneration: replication is only part of the story. Diabetes 59:2340-2348

20. Kheradmand T, Wang S, Gibly RF et al (2011) Permanent protection of PLG scaffold transplanted allogeneic islet grafts in diabetic mice treated with ECDI-fixed donor splenocyte infusions. Biomaterials 32:4517-4524

21. Aguayo-Mazzucato C, Bonner-Weir S (2010) Stem cell therapy for type 1 diabetes mellitus. Nat Rev Endocrinol 6:139-148

22. Blomeier H, Zhang X, Rives C et al (2006) Polymer scaffolds as synthetic microenvironments for extrahepatic islet transplantation. Transplantation 82:452-459

23. Berman DM, O'Neil JJ, Coffey LC et al (2009) Long-term survival of nonhuman primate islets implanted in an omental pouch on a biodegradable scaffold. Am J Transplant 9:91-104

24. Merani S, Toso C, Emamaullee J, Shapiro AM (2008) Optimal implantation site for pancreatic islet transplantation. Br J Surg 95:1449-1461

25. Contreras JL (2008) Extrahepatic transplant sites for islet xenotransplantation. Xenotransplantation 15:99-101
26. Tze WJ, Tai J (1989) Immunological studies in diabetic rat recipients with a pancreatic islet cell allograft in the brain. Transplantation 47:1053-1057

27. Whittington KB, Solomon SS, Lu ZN, Selawry HP (1991) Islet allografts in the cryptorchid testes of spontaneously diabetic BB/ Wor dp rats: response to glucose, glipizide, and arginine. Endocrinology 128:2671-2677

28. Echeverri GJ, McGrath K, Bottino R et al (2009) Endoscopic gastric submucosal transplantation of islets (ENDO-STI): technique and initial results in diabetic pigs. Am $\mathrm{J}$ Transplant 9:2485-2496

29. Perez VL, Caicedo A, Berman DM et al (2011) The anterior chamber of the eye as a clinical transplantation site for the treatment of diabetes: a study in a baboon model of diabetes. Diabetologia 54:1121-1126

30. Perez-Basterrechea $M$, Briones RM, Alvarez-Viejo $M$ et al (2009) Plasma-fibroblast gel as scaffold for islet transplantation. Tissue Eng Part A 15:569-577

31. Lim JY, Min BH, Kim BG et al (2009) A fibrin gel carrier system for islet transplantation into kidney subcapsule. Acta Diabetol 46:243-248

32. Hiscox AM, Stone AL, Limesand S, Hoying JB, Williams SK (2007) An islet-stabilizing implant constructed using a preformed vasculature. Tissue Eng Part A 14:433-440

33. Beck J, Angus R, Madsen B, Britt D, Vernon B, Nguyen KT (2007) Islet encapsulation: strategies to enhance islet cell functions. Tissue Eng 13:589-599

34. Murua A, Portero A, Orive G, Hernández RM, de Castro M, Pedraz JL (2008) Cell microencapsulation technology: towards clinical application. J Control Release 132:76-83

35. Lai Y, Schneider D, Kidszun A et al (2005) Vascular endothelial growth factor increases functional beta-cell mass by improvement of angiogenesis of isolated human and murine pancreatic islets. Transplantation 79:1530-1536

36. Olsson R, Maxhuni A, Carlsson P-O (2006) Revascularization of transplanted pancreatic islets following culture with stimulators of angiogenesis. Transplantation 82:340-347

37. Wang W, Gu Y, Tabata Yet al (2002) Reversal of diabetes in mice by xenotransplantation of a bioartificial pancreas in a prevascularized subcutaneous site. Transplantation 73:122-129

38. Balamurugan AN, Gu Y, Tabata Yet al (2003) Bioartificial pancreas transplantation at prevascularized intermuscular space: effect of angiogenesis induction on islet survival. Pancreas 26:279-285

39. Song HJ, Xue WJ, Li Y et al (2010) Prolongation of islet graft survival using concomitant transplantation of islets and vascular endothelial cells in diabetic rats. Transplant Proc 42:2662-2665

40. Thomas FT, Contreras JL, Bilbao G, Ricordi C, Curiel D, Thomas JM (1999) Anoikis, extracellular matrix, and apoptosis factors in isolated cell transplantation. Surgery 126:299-304

41. Kaido T, Yebra M, Cirulli V, Montgomery AM (2004) Regulation of human beta-cell adhesion, motility, and insulin secretion by collagen IV and its receptor $\alpha_{1} \beta_{1}$. J Biol Chem 279:5376253769

42. Ghofaili KA, Fung M, Ao Z et al (2007) Effect of exenatide on beta cell function after islet transplantation in type 1 diabetes. Transplantation 83:24-28

43. Giannoukakis N, Mi Z, Rudert WA, Gambotto A, Trucco M, Robbins P (2000) Prevention of beta cell dysfunction and apoptosis activation in human islets by adenoviral gene transfer of the insulin-like growth factor I. Gene Ther 7:2015-2022

44. Johansson M, Olerud J, Jansson L, Carlsson PO (2009) Prolactin treatment improves engraftment and function of transplanted pancreatic islets. Endocrinology 150:1646-1653

45. Rivas-Carrillo JD, Soto-Gutierrez A, Navarro-Alvarez N et al (2007) Cell-permeable pentapeptide V5 inhibits apoptosis and 
enhances insulin secretion, allowing experimental single-donor islet transplantation in mice. Diabetes 56:1259-1267

46. Gangemi A, Salehi P, Hatipoglu B et al (2008) Islet transplantation for brittle type 1 diabetes: the UIC protocol. Am J Transplant 8:1250-1261

47. Pollauf EJ, Kim KK, Pack DW (2005) Small-molecule release from poly(D,L-lactide)/poly(D,L-lactide-co-glycolide) composite microparticles. J Pharm Sci 94:2013-2022

48. Chen RR, Silva EA, Yuen WW, Mooney DJ (2007) Spatio-temporal VEGF and PDGF delivery patterns blood vessel formation and maturation. Pharm Res 24:258-264

49. Rives CB, des Rieux A, Zelivyanskaya M, Stock SR, Lowe WL Jr, Shea LD (2009) Layered PLG scaffolds for in vivo plasmid delivery. Biomaterials 30:394-401

50. Mellor AL, Munn DH (2008) Creating immune privilege: active local suppression that benefits friends, but protects foes. Nat Rev Immunol 8:74-80

51. Wood KJ, Sakaguchi S (2003) Regulatory T cells in transplantation tolerance. Nat Rev Immunol 3:199-210

52. Olson JK, Croxford JL, Miller SD (2001) Virus-induced autoimmunity: potential role of viruses in initiation, perpetuation, and progression of $\mathrm{T}$ cell-mediated autoimmune disease. Viral Immunol 14:227-250

53. Dufour JM, Lord SJ, Kin T et al (2008) Comparison of successful and unsuccessful islet/Sertoli cell cotransplant grafts in streptozotocin-induced diabetic mice. Cell Transplant 16:1029-1038

54. van Duivenvoorde LM, van Mierlo GJ, Boonman ZF, Toes RE (2006) Dendritic cells: vehicles for tolerance induction and prevention of autoimmune diseases. Immunobiology 211:627632

55. Banchereau J, Briere F, Caux C et al (2000) Immunobiology of dendritic cells. Annu Rev Immunol 18:767-811

56. Fu F, Li Y, Qian S et al (1996) Costimulatory molecule-deficient dendritic cell progenitors (MHC class $\mathrm{II}^{+}, \mathrm{CD} 80^{\mathrm{dim}}, \mathrm{CD} 86^{-}$) prolong cardiac allograft survival in nonimmunosuppressed recipients. Transplantation 62:659-665

57. Ito T, Yang M, Wang YH et al (2007) Plasmacytoid dendritic cells prime IL-10-producing $\mathrm{T}$ regulatory cells by inducible costimulator ligand. J Exp Med 204:105-115

58. Colonna M, Trinchieri G, Liu YJ (2004) Plasmacytoid dendritic cells in immunity. Nat Immunol 5:1219-1226

59. Garrovillo M, Ali A, Oluwole SF (1999) Indirect allorecognition in acquired thymic tolerance: induction of donor-specific tolerance to rat cardiac allografts by allopeptide-pulsed host dendritic cells. Transplantation 68:1827-1834

60. Sato K, Yamashita N, Baba M, Matsuyama T (2003) Modified myeloid dendritic cells act as regulatory dendritic cells to induce anergic and regulatory T cells. Blood 101:3581-3589

61. Sato K, Yamashita N, Baba M, Matsuyama T (2003) Regulatory dendritic cells protect mice from murine acute graft-versus-host disease and leukemia relapse. Immunity 18:367-379

62. Piccirillo CA, Thornton AM (2004) Cornerstone of peripheral tolerance: naturally occurring $\mathrm{CD} 4{ }^{+} \mathrm{CD} 25^{+}$regulatory $\mathrm{T}$ cells. Trends Immunol 25:374-380

63. Shevach EM (2009) Mechanisms of Foxp $3^{+}$T regulatory cellmediated suppression. Immunity 30:636-645

64. Belkaid Y (2007) Regulatory T cells and infection: a dangerous necessity. Nat Rev Immunol 7:875-888

65. Nakamura K, Kitani A, Strober W (2001) Cell contact-dependent immunosuppression by $\mathrm{CD} 4{ }^{+} \mathrm{CD} 25^{+}$regulatory T cells is mediated by cell surface-bound transforming growth factor beta. J Exp Med 194:629-644

66. Zhang N, Schroppel B, Lal G et al (2009) Regulatory T cells sequentially migrate from inflamed tissues to draining lymph nodes to suppress the alloimmune response. Immunity 30:458469
67. Pothoven KL, Kheradmand T, Yang Q et al (2010) Rapamycinconditioned donor dendritic cells differentiate $\mathrm{CD} 4{ }^{+} \mathrm{CD} 25^{+} \mathrm{Foxp}^{+}$ $\mathrm{T}$ cells in vitro with TGF- $\beta 1$ for islet transplantation. Am J Transplant 10:1774-1784

68. Luo X, Pothoven KL, McCarthy D et al (2008) ECDI-fixed allogeneic splenocytes induce donor-specific tolerance for longterm survival of islet transplants via two distinct mechanisms. Proc Natl Acad Sci USA 105:14527-14532

69. Luo X, Tarbell KV, Yang H et al (2007) Dendritic cells with TGF$\beta 1$ differentiate naive $\mathrm{CD} 4^{+} \mathrm{CD} 25^{-} \mathrm{T}$ cells into islet-protective Foxp $^{+}$regulatory T cells. Proc Natl Acad Sci USA 104:28212826

70. Maccario R, Podesta M, Moretta A et al (2005) Interaction of human mesenchymal stem cells with cells involved in alloantigenspecific immune response favors the differentiation of $\mathrm{CD}^{+} \mathrm{T}$ cell subsets expressing a regulatory/suppressive phenotype. Haematologica 90:516-525

71. Di Nicola M, Carlo-Stella C, Magni M et al (2002) Human bone marrow stromal cells suppress T-lymphocyte proliferation induced by cellular or nonspecific mitogenic stimuli. Blood 99:3838-3843

72. Berman DM, Willman MA, Han D et al (2010) Mesenchymal stem cells enhance allogeneic islet engraftment in nonhuman primates. Diabetes 59:2558-2568

73. Adams DO (1989) Molecular interactions in macrophage activation. Immunol Today 10:33-35

74. Corbett JA, Sweetland MA, Wang JL, Lancaster JR Jr, McDaniel ML (1993) Nitric oxide mediates cytokine-induced inhibition of insulin secretion by human islets of Langerhans. Proc Natl Acad Sci USA 90:1731-1735

75. Nagata S, Suda T (1995) Fas and Fas ligand: lpr and gld mutations. Immunol Today 16:39-43

76. Arnush M, Scarim AL, Heitmeier MR, Kelly CB, Corbett JA (1998) Potential role of resident islet macrophage activation in the initiation of autoimmune diabetes. J Immunol 160:26842691

77. Contreras JL, Eckstein C, Smyth CA et al (2004) Activated protein $\mathrm{C}$ preserves functional islet mass after intraportal transplantation: a novel link between endothelial cell activation, thrombosis, inflammation, and islet cell death. Diabetes 53:2804-2814

78. Akima S, Hawthorne WJ, Favaloro E et al (2009) Tirofiban and activated protein $\mathrm{C}$ synergistically inhibit the Instant Blood Mediated Inflammatory Reaction (IBMIR) from allogeneic islet cells exposure to human blood. Am J Transplant 9:15331540

79. Cui W, Wilson JT, Wen J et al (2009) Thrombomodulin improves early outcomes after intraportal islet transplantation. Am J Transplant 9:1308-1316

80. Gordon S (2003) Alternative activation of macrophages. Nat Rev Immunol 3:23-35

81. Cassatella MA, Meda L, Bonora S, Ceska M, Constantin G (1993) Interleukin 10 (IL-10) inhibits the release of proinflammatory cytokines from human polymorphonuclear leukocytes. Evidence for an autocrine role of tumor necrosis factor and IL-1 $\beta$ in mediating the production of IL8 triggered by lipopolysaccharide. J Exp Med 178:22072211

82. Sun L, Guo RF, Newstead MW, Standiford TJ, Macariola DR, Shanley TP (2009) Effect of IL-10 on neutrophil recruitment and survival after Pseudomonas aeruginosa challenge. Am J Respir Cell Mol Biol 41:76-84

83. Aviles MO, Lin CH, Zelivyanskaya $\mathrm{M}$ et al (2010) The contribution of plasmid design and release to in vivo gene expression following delivery from cationic polymer modified scaffolds. Biomaterials 31:1140-1147 
84. Ali OA, Huebsch N, Cao L, Dranoff G, Mooney DJ (2009) Infection-mimicking materials to program dendritic cells in situ. Nat Mater 8:151-158

85. Viney JL, Mowat AM, O’Malley JM, Williamson E, Fanger NA (1998) Expanding dendritic cells in vivo enhances the induction of oral tolerance. J Immunol 160:5815-5825

86. Shields JD, Kourtis IC, Tomei AA, Roberts JM, Swartz MA (2010) Induction of lymphoidlike stroma and immune escape by tumors that express the chemokine CCL21. Science 328:749752

87. Battaglia M, Stabilini A, Draghici E et al (2006) Rapamycin and interleukin-10 treatment induces $\mathrm{T}$ regulatory type 1 cells that mediate antigen-specific transplantation tolerance. Diabetes 55:40-49

88. Kimura F, Gotoh M, Tanaka T et al (2002) Locally expressed CTLA4-Ig in a pancreatic beta-cell line suppresses accelerated graft rejection response induced by donor-specific transfusion. Diabetologia 45:831-840

89. Papeta N, Chen T, Vianello F et al (2007) Long-term survival of transplanted allogeneic cells engineered to express a $\mathrm{T}$ cell chemorepellent. Transplantation 83:174-183

90. Reddy ST, van der Vlies AJ, Simeoni E et al (2007) Exploiting lymphatic transport and complement activation in nanoparticle vaccines. Nat Biotechnol 25:1159-1164

91. Zheng XX, Markees TG, Hancock WW et al (1999) CTLA4 signals are required to optimally induce allograft tolerance with combined donor-specific transfusion and anti-CD154 monoclonal antibody treatment. J Immunol 162:4983-4990

92. Pearson TC, Madsen JC, Larsen CP, Morris PJ, Wood KJ (1992) Induction of transplantation tolerance in adults using donor antigen and anti-CD4 monoclonal antibody. Transplantation $54: 475-483$

93. Punch JD, Tono T, Qin L, Bishop DK, Bromberg JS (1998) Tolerance induction by anti-CD2 plus anti-CD3 monoclonal antibodies: evidence for an IL-4 requirement. J Immunol 161:1156-1162

94. Xu L, Villain M, Galin FS, Araga S, Blalock JE (2001) Prevention and reversal of experimental autoimmune myasthenia gravis by a monoclonal antibody against acetylcholine receptorspecific T cells. Cell Immunol 208:107-114

95. Braley-Mullen H, Tompson JG, Sharp GC, Kyriakos M (1980) Suppression of experimental autoimmune thyroiditis in guinea pigs by pretreatment with thyroglobulin-coupled spleen cells. Cell Immunol 51:408-413

96. Dua HS, Gregerson DS, Donoso LA (1992) Inhibition of experimental autoimmune uveitis by retinal photoreceptor antigens coupled to spleen cells. Cell Immunol 139:292-305

97. Vandenbark AA, Vainiene M, Ariail K, Miller SD, Offner H (1996) Prevention and treatment of relapsing autoimmune encephalomyelitis with myelin peptide-coupled splenocytes. J Neurosci Res 45:430-438

98. Miller SD, Turley DM, Podojil JR (2007) Antigen-specific tolerance strategies for the prevention and treatment of autoimmune disease. Nat Rev Immunol 7:665-677

99. Nano R, Clissi B, Melzi R et al (2005) Islet isolation for allotransplantation: variables associated with successful islet yield and graft function. Diabetologia 48:906-912

100. Noguchi H (2010) Production of pancreatic beta-cells from stem cells. Curr Diabetes Rev 6:184-190

101. Hering BJ, Walawalkar N (2009) Pig-to-nonhuman primate islet xenotransplantation. Transpl Immunol 21:81-86 